\title{
Pioneer settlement of the cold-water coral Desmophyllum dianthus (Esper, 1794) on plastic
}

\author{
Elisa Bergami ${ }^{1} \cdot$ Erik Caroselli $^{2,6}{ }^{(10} \cdot$ Lisa Vaccari $^{3} \cdot$ Ilaria Corsi $^{1}$ \\ Alexander Semenov ${ }^{4} \cdot$ Armando Macali $^{5}$
}

Received: 8 March 2021/Accepted: 10 June 2021/Published online: 22 June 2021

(C) The Author(s) 2021

\begin{abstract}
Larval settlement is a critical step for sessile benthic species such as corals, whose ability to thrive on diverse natural and anthropogenic substrates may lead to a competitive advantage in the colonization of new environments with respect to a narrow tolerance for a specific kind of substratum. Plastic debris, widespread in marine waters, provides a large, motile, and solid substratum supporting a highly diverse biological community. Here we present the first observation of a floating plastic bottle colonized by the deep-sea coral Desmophyllum dianthus. The density pattern and co-occurring species composition
\end{abstract}

Topic Editor Anastazia Teresa Banaszak

Supplementary Information The online version contains supplementary material available at https://doi.org/10.1007/s00338021-02131-9.

Erik Caroselli

erik.caroselli@unibo.it

1 Department of Physical, Earth and Environmental Sciences, University of Siena, Via P. A. Mattioli 4, 53100 Siena, Italy

2 Marine Science Group, Department of Biological, Geological and Environmental Sciences, University of Bologna, Via Selmi 3, 40126 Bologna, Italy

3 Elettra-Sincrotrone Trieste S.C.p.A., S.S. 14 Km 163.5 in Area Science Park, 34149 Basovizza, Trieste, Italy

4 N. A. Pertsov White Sea Biological Research Station, Department of Biology, Lomonosov Moscow State University, Leninskie Gory, 1-12, Moscow, Russia 119991

5 Ichthyogenic Experimental Marine Centre (CISMAR), Department of Ecological and Biological Sciences, Tuscia University, 01016 Borgo Le Saline, Tarquinia, Italy

6 Fano Marine Center, The Inter-Institute Center for Research On Marine Biodiversity, Resources and Biotechnologies, Viale Adriatico 1/N, 61032 Fano, Italy suggest a pioneer behavior of this coral species, whose peculiar morphologic plasticity response when interacting with the plastic substrate (i.e., low density polyethylene) has not been observed before. The tolerance of $D$. dianthus for such plastic substrate may affect ecological processes in deep water environments, disrupting interspecific substrate competition in the benthic community.

Keywords Plastic debris - Scleractinian coral · Mediterranean Sea $\cdot$ Encrustation pattern $\cdot$ Substrate competition

\section{Introduction}

Factors such as habitat selection and larval recruitment may have profound implications for sessile benthic species such as corals, in which planktonic larvae constitute the dispersal stage of their life history (Burgess et al. 2012). The ability of corals to settle on diverse substrates, both natural and anthropogenic, confers a competitive advantage over species with a narrow tolerance for a specific kind of substratum (Dubé et al. 2016). For example, the coral species Oculina patagonica and Caryophyllia inornata are particularly successful in colonizing piers and metal wrecks, respectively, showing higher abundance than on natural substrata (Salomidi et al. 2013; Caroselli et al. 2015). Tubastraea corals can easily grow on concrete (Ho et al. 2017) and shipwrecks (Soares et al. 2020), and metal floating objects are a potential rafting substrate for corals (Hoeksema et al. 2012).

Plastic litter is pervasive in the marine environment and particularly macroplastic $(>1 \mathrm{~cm})$ provides a large and solid substratum which can support a biological community (Crocetta et al. 2020; De-La-Torre et al. 2021). Recent 
findings show a just preference for plastic substrates by benthic invertebrate larvae, also supported by a faster larval settlement that on natural and other artificial substrates (Goldstein et al. 2014; Chase et al. 2016; Pinochet et al. 2020). A few reports show the successful colonization of plastic debris by anthozoan species, including alcyionacean (Carugati et al. 2021) and scleractinian corals (Hoeksema et al. 2018), mostly on abandoned, lost or derelict fishing gear (e.g., Rech et al., 2016; Hoeksema and Hermanto 2018; Valderrama Ballesteros et al. 2018; Battaglia et al. 2019).

The role of plastic as a vector for macro-fauna dispersal is overlooked, although it may promote the long-distance spread of invasive species (both corals and associated microorganisms) over biogeographic barriers (Hoeksema et al. 2018) and alter macrobenthic community structure and ecology (de Carvalho-Souza et al. 2018; Lamb et al. 2018). The United Nations Environment Program (2019) recently underlined the need for more research focusing on the interactions between plastic and coral species at a global scale. Observations of plastic accumulation and interactions with cold-water corals in the Mediterranean region are particularly encouraged to clarify the potential impact of marine litter in deep-sea ecosystems (RamirezLlodra et al. 2013). Here we describe some puzzling aspects about the first observation of a pioneer settlement of the solitary, deep- and cold-water coral Desmophyllum dianthus (Esper, 1794) on a floating plastic bottle retrieved during a field campaign on the Central Mediterranean Sea (Thyrrhenian Sea).

\section{Materials and methods}

Data have been collected during the AQUATILIS Expedition at Ponza Island (Tyrrhenian Sea, Italy) in April 2018. The sampling site was located $0.8 \mathrm{~km}$ South-East of Ponza harbor, close to a group of emerged rocks ("Formiche Bank", $40^{\circ} 3^{\prime} 5.8^{\prime \prime} \mathrm{N}-12^{\circ} 58^{\prime} 41.0^{\prime \prime} \mathrm{E}$, Fig. 1), and characterized by a complex hydrodynamism that promotes vortex formation with the accumulation of plastic debris in the area (Macali et al. 2018). During a night dive, a floating hard yellow plastic bottle with a small piece of rope attached and fouling biota was collected for visual inspection. The plastic bottle was measured and photographed from several orientations to describe the degree of biofouling. Three pieces of the bottle were cut with scissors, washed in ultrapure water and processed for polymeric characterization by Attenuated Total Reflection Fourier-Transform Infrared (ATR-FTIR) spectroscopy (see ESM Material and Methods). Specimens of the fouling biota were also collected for species identification and morphometric analysis (see ESM Material and Methods).

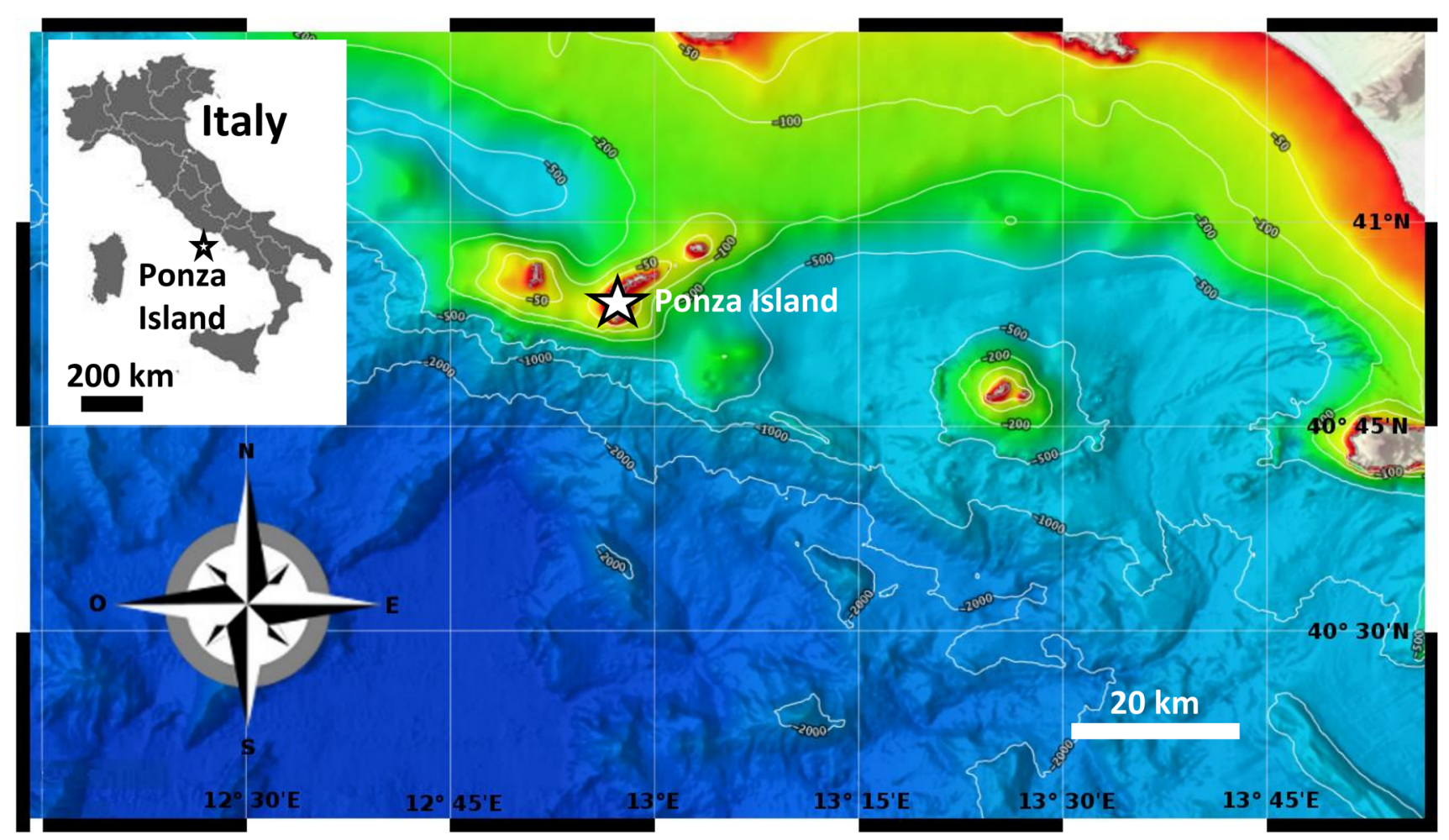

Fig. 1 Bathymetric map of the Central Tyrrhenian Sea and the study area (Ponza Island) 


\section{Results and discussion}

The plastic bottle measured $44.13 \times 25.88 \times 7.85 \mathrm{~cm}$ (Fig. 1a) and was marked by the label "Razzo" on the top lid, likely referred to the Brazilian company of household hygiene and cleaning products (www.razzo.com.br), which can be assumed as a potential origin. The plastic, possibly used as a subsurface mooring buoy at sea, was found intact, with negligible signs of weathered surface. Based on the
ATR-FTIR spectrum and a float test (see ESM results, ESM Fig. 1), the macroplastic was identified as a low density (LD) polyethylene (PE), one of the polymers mostly used in packaging industries (PlasticsEurope 2020) and the most common one found in marine waters worldwide (Cózar et al. 2014; Suaria et al. 2020).

Individuals $(n=6)$ of the solitary coral $D$. dianthus were found settled both on the hard plastic and on the rope attached (Fig. 2b, c). The only other two species attached
Fig. 2 a Hard plastic bottle collected at the Formiche Bank (Ponza Island, Central Tyrrhenian Sea); detail of $\mathbf{b}$ a specimen of $D$. dianthus settled on the plastic and $\mathbf{c}$ the extension of its basal plate $\left(b^{*}\right)$ on the plastic. $\mathbf{d}$ specimens of Lepas pectinata and $\mathbf{e}$ tubes of unidentified sessile polychaetes

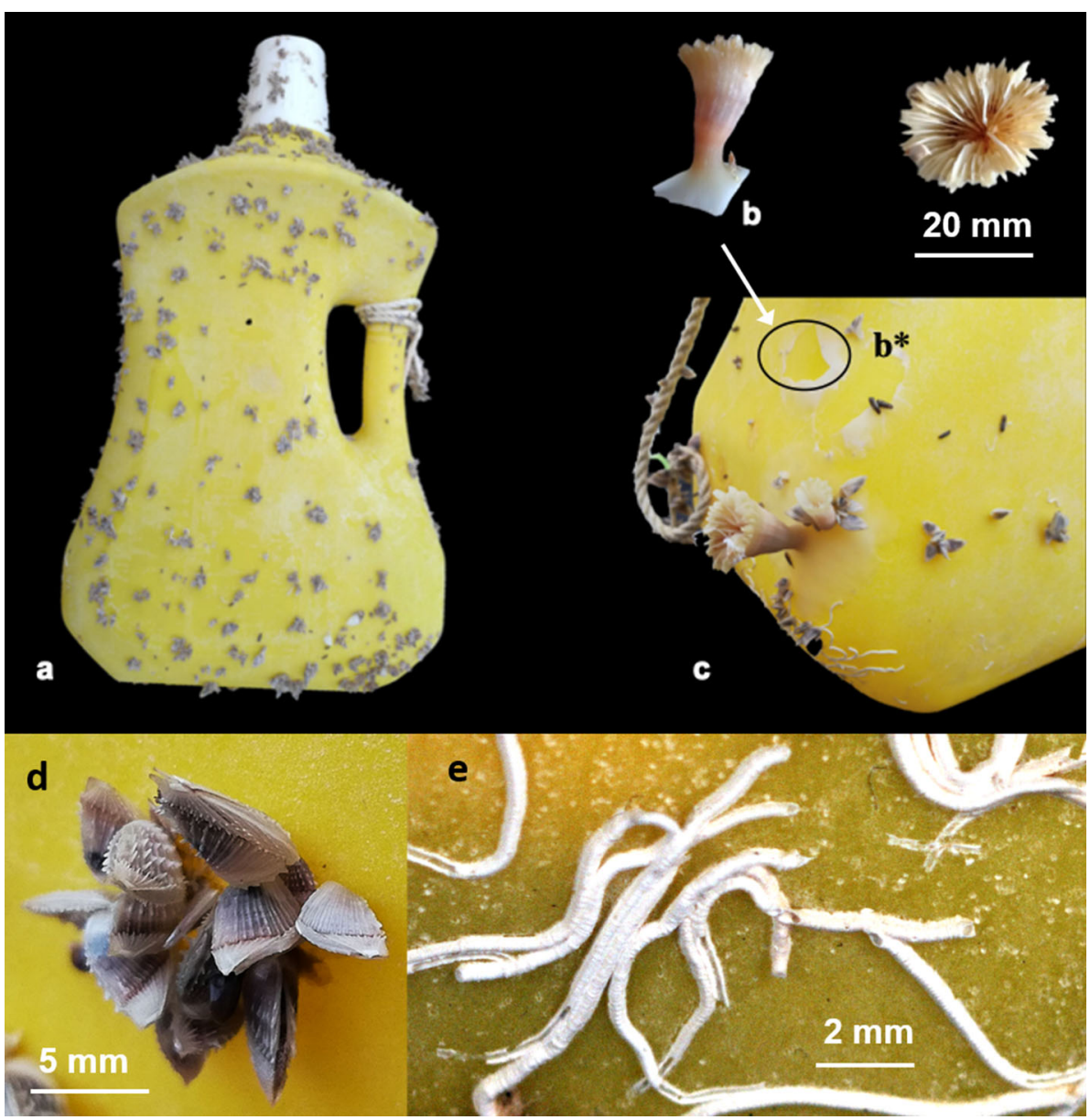

Table 1 Corallum greater diameter and height of each collected specimens of Desmophyllum dianthus with corresponding estimated age classes based on the two extreme growth rate estimates available $\left(0.5 \mathrm{~mm} \mathrm{yr}^{-1}\right.$ and $2 \mathrm{~mm} \mathrm{yr}^{-1}$; Risk et al. 2002; Adkins et al. 2004)

\begin{tabular}{llllll}
\hline Sample & Greater diameter $(\mathrm{mm})$ & Height $(\mathrm{mm})$ & Minimum estimated age $(\mathrm{yr})$ & Maximum estimated age $(\mathrm{yr})$ & Mean estimated age $(\mathrm{yr})^{1}$ \\
\hline P01 & 25.0 & 25 & 12.5 & 50.0 & 20.0 \\
P02 & 1.5 & 1.5 & 0.8 & 3.0 & 1.2 \\
P03 & 16.5 & 23.5 & 11.8 & 47.0 & 18.8 \\
P04 & 13.5 & 23.5 & 11.8 & 47.0 & 18.8 \\
P05 & 5.5 & 9.0 & 4.5 & 18.0 & 7.2 \\
P06 & 8.0 & 12.5 & 6.3 & 25.0 & 10.0 \\
\hline
\end{tabular}

The mean indicated was estimated using the mean value of the two growth rate estimates $\left(1.25{\left.\mathrm{~mm} \mathrm{yr}^{-1}\right)}^{-1}\right.$ 
Fig. 3 Detail of the extension of $D$. dianthus basal plates on the macroplastic. The image was edited to emphasize the coral basal plates on the anthropogenic substratum. a yellow color desaturated; b original color with basal plate outlined in red

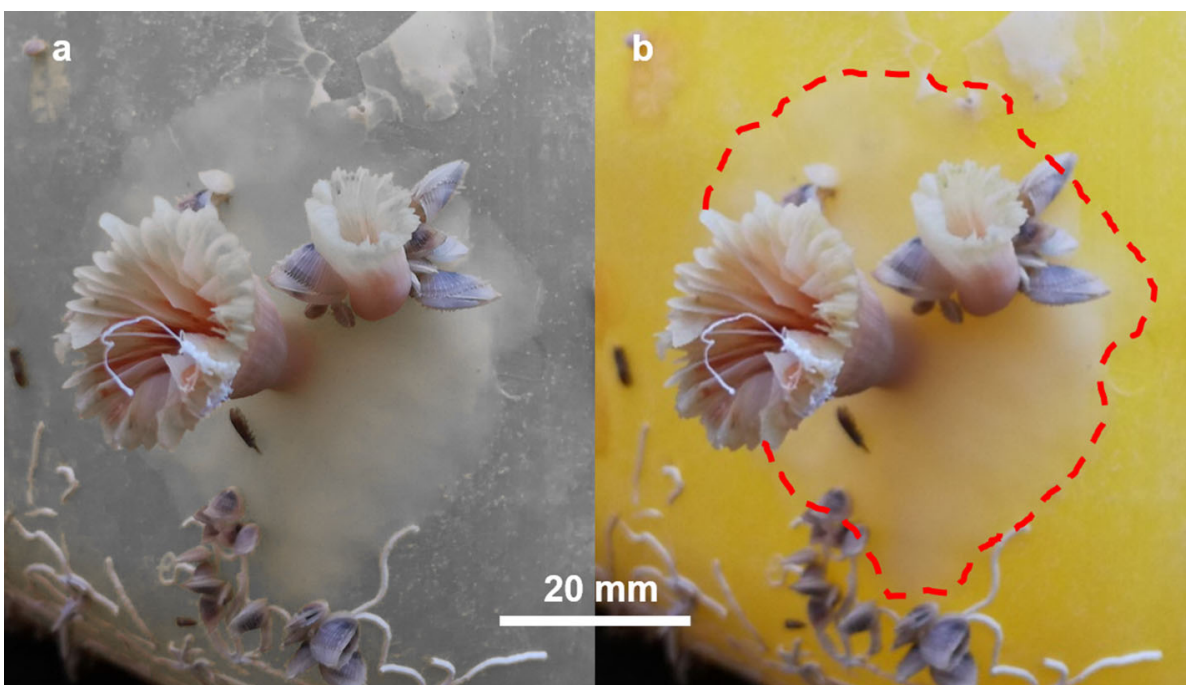

were the cirriped Lepas pectinata and tubes of unidentified sessile polychaetes (Fig. 2d, e). Barnacles of the genus Lepas are commonly found on floating plastic debris where they serve as foundation species (Gil \& Pfaller 2016), thus they likely colonized the macroplastic when it was floating at the surface. On the contrary, $D$. dianthus most likely had colonized the macroplastic while it was submerged and attached to the seafloor with the rope. Desmophyllum dianthus is a cold-water scleractinian coral, occurring in the upper bathyal zone (200-2500 m) and frequently associated with frame-building species, like $D$. pertusum and Madrepora oculata (Roberts et al. 2009), contributing to the reef framework as aggregated colonies or "clumps of specimens". Desmophyllum dianthus is reported to occur in deep waters at hundreds to thousands of meters depth, with the shallowest reported depth being $7 \mathrm{~m}$ depth in subantarctic waters (Försterra et al. 2005) and $100 \mathrm{~m}$ in the Mediterranean Sea (Bo et al. 2017).

According to morphological measurements, the age of coral specimens was estimated based on available growth rates of $D$. dianthus (Table 1), a slow-growing coral $\left(0.5-2.0 \mathrm{~mm} \mathrm{yr}^{-1}\right.$ in height) with a long lifespan up to 200 years (Risk et al. 2002; Adkins et al. 2004). The plastic bottle can be dated an average of 20 years (12.5-50.0) as the age of the oldest coral observed (i.e., P01 in Table 1). The presence of corals of very different size classes and corresponding ages (Table 1) indicates the multi-year residence of the plastic at sea, under environmental conditions which favored the settlement during multiple reproduction events. Given their depth distribution which does not reach surface waters, corals most likely settled on the plastic bottle while it was fixed on the seafloor. The detachment of the bottle can thus be dated about 1.2 year $(0.8-3.0)$ as the age of the youngest coral observed (i.e., P02 in Table 1, because younger corals would be observed if the bottle was still on the bottom for further time).

The presence of coral specimens of different size and age on the plastic may be explained by further independent colonization, supporting the hypothesis of this LD PE bottle as suitable substrate for the species. Notably, all coral specimens showed an exceptional lateral extension of the basal plate (see for comparison Gori et al. 2016), which covered the surrounding area for several $\mathrm{cm}^{-2}$ around each corallum (Fig. 2b, c), covering most of the available smooth surface of the plastic bottle (Fig. 3). This characteristic has never been observed for this species on natural substrata, possibly representing a specific response to the plastic surface. A wider basal plate could be advantageous to prevent settlement of other organisms on the free available space, and indeed no other species characteristic of deep sea environments were found on the plastic bottle. This may indicate a pioneer settlement of $D$. dianthus when a free plastic substratum becomes available at depth, preventing the possibilities of colonization by other species. The population of $D$. diantus surrounding the location where the bottle was abandoned on the seafloor may have been dominant, contributing to successful repeated settlement on the plastic. A further explanation for the larger basal plate may be that a larger attachment area gives a better holdfast, which may be more critical on a smooth surface like plastic.

Our report from the Mediterranean Sea represents the first evidence of a floating plastic bottle colonized by the cold-water coral $D$. dianthus, displaying an atypical growth pattern never observed on natural substrates. The absence of other coral species as well as other encrusting fouling, despite the size of the plastic and its long residence time at sea, suggests a possible pioneer behavior of $D$. dianthus, which seems to compete for substrate through a rapid and 
wide extension of its basal plate. Considering that $D$. dianthus has been listed as Endangered in the latest IUCN report on the conservation status of Mediterranean Anthozoa (Bo et al. 2017), being threatened by habitat degradation due to anthropogenic activities, its tolerance to plastic substrates may ironically favor its dispersal. Nevertheless, this tolerance for plastic substrate deserves further investigation, both for its possible interactions with ecological processes in deep water environments and for its potential application in the field of reef-restoration, in this case targeted on deep-water environments.

Acknowledgements The authors acknowledge the CERIC-ERIC Consortium for the access to experimental facilities and financial support (beamtime Number-20192144) and the Aquatilis Association for the financial support of the expedition.

Funding Open access funding provided by Alma Mater Studiorum Università di Bologna within the CRUI-CARE Agreement.

\section{Declarations}

Conflict of interest The authors declare that they have no conflict of interest.

Open Access This article is licensed under a Creative Commons Attribution 4.0 International License, which permits use, sharing, adaptation, distribution and reproduction in any medium or format, as long as you give appropriate credit to the original author(s) and the source, provide a link to the Creative Commons licence, and indicate if changes were made. The images or other third party material in this article are included in the article's Creative Commons licence, unless indicated otherwise in a credit line to the material. If material is not included in the article's Creative Commons licence and your intended use is not permitted by statutory regulation or exceeds the permitted use, you will need to obtain permission directly from the copyright holder. To view a copy of this licence, visit http://creativecommons. org/licenses/by/4.0/

\section{References}

Adkins JF, Henderson GM, Wang SL, O'Shea S, Mokadem F (2004) Growth rates of the deep-sea scleractinia Desmophyllum cristagalli and Enallopsammia rostrata. Earth Planet Sci Lett 227:481-490

Battaglia P, Consoli P, Ammendolia G, D'Alessandro M, Bo M, Vicchio TM, Pedà C, Cavallaro M, Andaloro F, Romeo T (2019) Colonization of floats from submerged derelict fishing gears by four protected species of deep-sea corals and barnacles in the Strait of Messina (central Mediterranean Sea). Mar Poll Bull 148:61-65

Bo M, Numa C, del Mar OM, Orejas C, Garrabou J, Cerrano C, Kružic P, Antoniadou C, Aguilar R, Kipson S, Linares C, Terrón-Sigler A, Brossard J, Kersting D, Casado-Amezúa P, García S, Goffredo S, Ocaña O, Caroselli E, Maldonado M, Bavestrello G, Cattaneo-Vietti R, Özalp B (2017) Overview of the conservation status of Mediterranean anthozoa. IUCN, Malaga
Burgess SC, Treml EA, Marshall DJ (2012) How do dispersal costs and habitat selection influence realized population connectivity? Ecology 93:1378-1387

Caroselli E, Nanni V, Levy O, Falini G, Dubinsky Z, Goffredo S (2015) Latitudinal variations in biometry and population density of a mediterranean solitary coral. Limnol Oceanogr 60:1356-1370

Carugati L, Bramanti L, Giordano B, Pittura L, Cannas R, Follesa MC, Pusceddu A, Cau A (2021) Colonization of plastic debris by the long-lived precious red coral Corallium rubrum: New insights on the "plastic benefits" paradox. Mar Pollut Bull 165:112104

Chase AL, Dijkstra JA, Harris LG (2016) The influence of substrate material on ascidian larval settlement. Mar Poll Bull 106:35-42

Cózar A, Echevarría F, González-Gordillo JI, Irigoien X, Úbeda B, Hernández-León S, Palma ÁT, Navarro S, García-de-Lomas J, Ruiz A, Fernández-de-Puelles ML, Duarte CM (2014) Plastic debris in the open ocean. Proc Natl Acad Sci USA 111:10239-10244

Crocetta F, Riginella E, Lezzi M, Tanduo V, Balestrieri L, Rizzo L (2020) Bottom-trawl catch composition in a highly polluted coastal area reveals multifaceted native biodiversity and complex communities of fouling organisms on litter discharge. Mar Environ Res 155:104875

de Carvalho-Souza GF, Llope M, Tinôco MS, Medeiros DV, MaiaNogueira R, Sampaio CLS (2018) Marine litter disrupts ecological processes in reef systems. Mar Poll Bull 133:464-471

De-la-Torre GE, Dioses-Salinas DC, Pérez-Baca BL, Millones Cumpa LA, Pizarro-Ortega CI, Torres FG, Gonzales KN, Santillán L (2021) Marine macroinvertebrates inhabiting plastic litter in Peru. Mar Pollut Bull 167:112296

Dubé CE, Boissin E, Planes S (2016) Overgrowth of living scleractinian corals by the hydrocoral Millepora platyphylla in Moorea, French Polynesia. Mar Biodivers 46:329-330

Försterra G, Beuck L, Häussermann V, Freiwald A (2005) Shallowwater Desmophyllum dianthus (Scleractinia) from Chile: characteristics of the biocoenoses, the bioeroding community, heterotrophic interactions and (paleo)-bathymetric implications. In: Freiwald A, Murray Roberts J (eds) Cold-water corals and ecosystems. Springer, Heidelberg, pp 937-977

Gil MA, Pfaller JB (2016) Oceanic barnacles act as foundation species on plastic debris: implications for marine dispersal. Sci Rep 6:19987

Goldstein M, Carson H, Eriksen M (2014) Relationship of diversity and habitat area in North Pacific plastic-associated rafting communities. Mar Biol 161:1441-1453

Gori A, Ferrier-Pagès C, Hennige SJ, Murray F, Rottier C, Wicks LC, Roberts JM (2016) Physiological response of the cold-water coral Desmophyllum dianthus to thermal stress and ocean acidification. PeerJ 4:e1606

Ho MJ, Hsu CM, Chen CA (2017) Wall of orange cup coral, Tubastraea coccinea, at the inlet breakwaters of a nuclear power plant, southern Taiwan. Mar Biodivers 47:163-164

Hoeksema BW, Hermanto B (2018) Plastic nets as substrate for reef corals in Lembeh Strait. Indonesia Coral Reefs 37:631

Hoeksema BW, Roos PJ, Cadee GC (2012) Trans-Atlantic rafting by the brooding reef coral Favia fragum on man-made flotsam. Mar Ecol Prog Ser 445:209-218

Hoeksema BW, Pedoja K, Poprawski Y (2018) Long-distance transport of a West Atlantic stony coral on a plastic raft. Ecology 99:2402-2404

Jung MR, Horgen FD, Orski SV, Rodriguez CV, Beers KL, Balazs GH, Jones TT, Work TM, Brignac KC, Royer SJ, Hyrenbach KD, Jensen BA, Lynch JM (2018) Validation of ATR FT-IR to identify polymers of plastic marine debris, including those ingested by marine organisms. Mar Poll Bull 127:704-716 
Lamb JB, Willis BL, Fiorenza EA, Couch CS, Howard R, Rader DN, True JD, Kelly LA, Ahmad A, Jompa J, Harvell CD (2018) Plastic waste associated with disease on coral reefs. Science 359:460-462

Macali A, Semenov A, Venuti V, Crupi V, D’Amico F, Rossi B, Corsi I, Bergami E (2018) Episodic records of jellyfish ingestion of plastic items reveal a novel pathway for trophic transference of marine litter. Sci Rep 8:6105

Pinochet J, Urbina MA, Lagos ME (2020) Marine invertebrate larvae love plastics: Habitat selection and settlement on artificial substrates. Environ Pollut 257:113571

PlasticsEurope (2020) Plastics - the facts 2020. An analysis of European plastics production, demand and waste data. Association of Plastics Manufacturers. https://www.plasticseurope.org/ en/resources/publications/4312-plastics-facts-2020

Ramirez-Llodra E, De Mol B, Company JB, Coll M, Sardà F (2013) Effects of natural and anthropogenic processes in the distribution of marine litter in the deep Mediterranean Sea. Progr Oceanogr 118:273-287

Rech S, Borrell Y, García-Vazquez E (2016) Marine litter as a vector for non-native species: what we need to know. Mar Poll Bull 113:40-43

Risk MJ, Heikoop JM, Snow MG, Beukens R (2002) Lifespans and growth patterns of two deep-sea corals: Primnoa resedaeformis and Desmophyllum cristagalli. Hydrobiologia 471:125-131
Roberts J, Wheeler AJ, Freiwald A, Cairns SD (2009) Cold-water corals: The biology and geology of deep-sea coral habitats. In: Murray Roberts J (ed) Cold-Water Corals: The Biology and Geology of Deep-Sea Coral Habitats. Cambridge University Press, Cambridge, pp 20-66

Salomidi M, Katsanevakis S, Issaris Y, Tsiamis K, Katsiaras N (2013) Anthropogenic disturbance of coastal habitats promotes the spread of the introduced scleractinian coral Oculina patagonica in the Mediterranean Sea. Biol Invasions 15:1961-1971

Soares MdO, Salani S, Paiva SV, Braga MDA (2020) Shipwrecks help invasive coral to expand range in the Atlantic Ocean. Mar Pollut Bull 158:111394

Suaria G, Perold V, Lee JR, Lebouard F, Aliani S, Ryan PG (2020) Floating macro- and microplastics around the Southern Ocean: results from the Antarctic circumnavigation expedition. Environ Int, 136: 105494

Valderrama Ballesteros L, Matthews JL, Hoeksema BW (2018) Pollution and coral damage caused by derelict fishing gear on coral reefs around Koh Tao, Gulf of Thailand. Mar Pollut Bull 135:1107-1116

Publisher's Note Springer Nature remains neutral with regard to jurisdictional claims in published maps and institutional affiliations. 